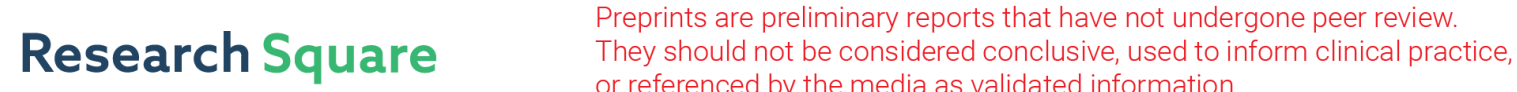 or referenced by the media as validated information. \\ Reconfigurable 2×1 CPW-Fed Rectangular Slot Antenna Array (RSAA) Based on Graphene For Wireless Communications
}

Dalia Elsheakh ( $\nabla$ daliaelsheakh@gmail.com )

Electronics Research Institute https://orcid.org/0000-0002-6168-7681

Osama Dardeer

Electronics Research Institute

\section{Research}

Keywords: Graphene, antenna array, reconfigurable, detection and wireless communication applications

Posted Date: June 28th, 2021

DOl: https://doi.org/10.21203/rs.3.rs-621748/v1

License: (c) (1) This work is licensed under a Creative Commons Attribution 4.0 International License.

Read Full License 


\title{
Reconfigurable 2×1 CPW-Fed Rectangular Slot Antenna Array (RSAA) Based on Graphene for Wireless Communications
}

\author{
Dalia Elsheakh ${ }^{(1),(2)}$ and Osama Dardeer ${ }^{(2)}$ \\ (1) Electrical Dept., Faculty of Engineering-Badr University, Badr University in Cairo. \\ (2) Microstrip Dept., Electronics Research Institute, 11843, El Nozha, Cairo, Egypt. \\ Correspondence: *Dalia Elsheakh; dalia-mohamed@buc.edu.eg / daliaelsheakh@eri.sci.eg
}

\begin{abstract}
This article presents a $2 \times 1 \mathrm{CPW}$ ultra wideband rectangular slot antenna array (UWB-RSAA) with modified circular slot shape to support high data rate for wireless communications applications. The proposed antenna array dimensions are $0.7 \lambda_{0} \times 0.8 \lambda_{0} \times 0.064 \lambda_{\circ}$ at the resonant frequency 1.8 $\mathrm{GHz}$ and it is fabricated on a commercially available rogers RO4003 substrate (with $\varepsilon_{\mathrm{r}}=3.5$ ), which is fed by using coplanar waveguide (CPW). A graphene layer is added on the other side of the substrate to achieve frequency reconfigurable and improve the antenna array gain. The $-10 \mathrm{~dB}$ impedance bandwidth of the RSAA extends from $1.7 \mathrm{GHz}$ to $2.6 \mathrm{GHz}$, from 3.2 to $3.8 \mathrm{GHz}$ and from $5.2 \mathrm{GHz}$ to $7 \mathrm{GHz}$ with peak gain of $7.5 \mathrm{dBi}$ at $6.5 \mathrm{GHz}$ at 0 Volt bias over the operating band with average gain of $4.5 \mathrm{dBi}$. When the graphene bias is increased to $20 \mathrm{Volt}$, the antenna bandwidth extend from $1 \mathrm{GHz}$ to $4 \mathrm{GHz}$ and from 5 to $7 \mathrm{GHz}$ with array peak gain $14 \mathrm{dBi}$ at 3.5 $\mathrm{GHz}$ and average gain $7.5 \mathrm{dBi}$. The proposed array achieved linear polarized behaviour over the operating bands to be suitable for short range UWB wireless communications and object detection. All simulation carried out using 3D high frequency structure simulator (HFSS) Ansys ver. 15.
\end{abstract}

Key words: Graphene, antenna array, reconfigurable, detection and wireless communication applications.

\section{Introduction}

Frequency tuning of the microwave systems has gained a great attention in the research field of antennas for wireless communications. Reconfigurable antenna array is one of the most important elements of the RF circuits system [1-4]. In addition, wide band antennas array with frequency reconfigurable could be served several selected frequency bands avoiding the unwanted frequencies. Reconfigurable antennas need less space in the RF system, resulting in multi-band 
integrated RF systems [6-7]. Several techniques have been used to achieve reconfigurable antennas array like using varactor diodes [8], PIN diodes [9], MEMS [10], and other techniques [11, 12].

Graphene is considered to be one of the most important and revolutionary materials of the $21^{\text {st }}$ century, with its characteristics and widespread applications. Graphene sheet as a honeycomb lattice arrangement of carbon atoms is First time of investigated done in 2004 [13]. The application of RF antennas based on graphene has had positive implications for wireless communication applications. Graphene has superior electrical properties that enable it to be a very promising material in researchs in different applications. Many researches have been presented on graphene applications for radio frequency (RF), microwave (MW), millimetre wave (MM) and tera hertz (THz) applications [13-15]. One of the most effective research areas utilized graphene sheet layer based on its tunable conductivity [16]. This tunable function is based on changing the applied DC bias voltage to the graphene sheet layer, which varies the chemical potential and hence the conductivity/resistance of it layer [17]. Many researches on high-quality graphene have progressed rapidly due to improvements in laboratory procedures that allows the production of graphene with controlled properties [22]. So, a great effort has been done in this area for designed array antenna with frequency reconfigurablity [18-21] and the proposed $2 \times 1$ recongurable antenna array is shown in Fig.1.

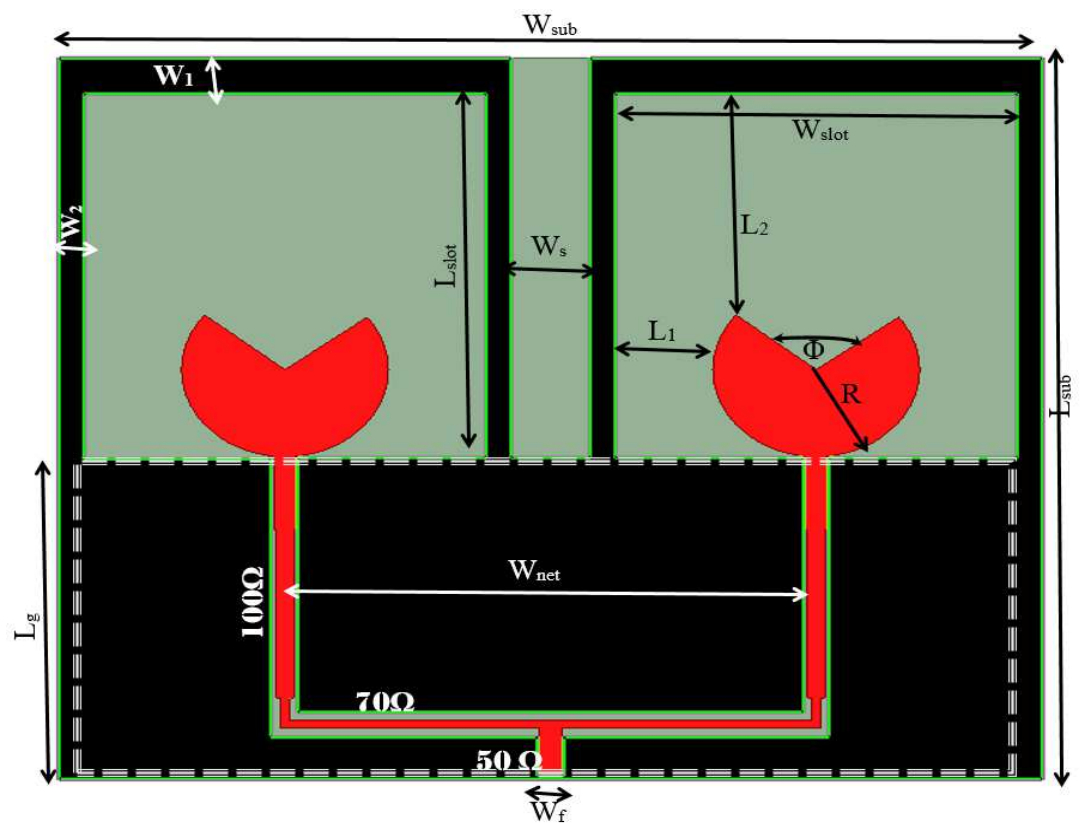

(a)

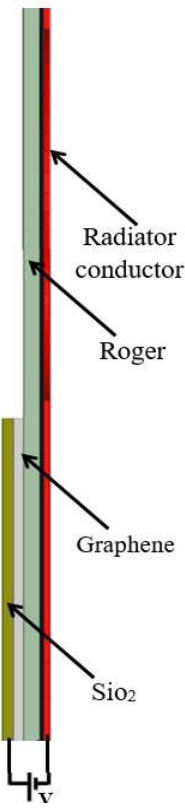

(b)

Fig. 1. (a) The structure geometry of the proposed $2 \times 1$ RSAA and (b) side view.

In this paper, reconfigurable $2 \times 1 \mathrm{CPW}$-fed RSAA with an acceptable gain is introduced. The array 
is fed by $3 \mathrm{~dB}$ CPW power divider, which makes the structure easy to integrate with other microwave circuit. A graphene pad sheet is placed beneath the feeding network to achieve the frequency reconfigurable action.

This article is organized as follows; section one is introduced the paper idea. While, section two presented the proposed RSAA design geometry. Section three discussed the graphene layer structure and its properties, then the experimental setup and results are presented with the comparison using the software tool results in section four. Section five illustrates the group delay results and object detection application, finally section six concludes and summarizes the results of the paper.

\section{Methods of Designing Antenna}

The cpw-fed proposed antenna array is printed on a dielectric substrate of Roger RO4003 with dielectric constant $\varepsilon_{\mathrm{r}}=3.5$ and $\tan \delta=0.0012$. The substrate has dimensions $\left(L_{s u b} \times W_{s u b}\right)$, and thickness of substrate is $0.8 \mathrm{~mm}$. CPW fed slot antennas are very puplar which exhebit broad bandwidth and aproperteate gain [23]. First design is a conventional $2 \times 1$ circular shape of monopole anttenna array, which is fed using 3-dB power divider cpw-fed network as shown in Fig. 2(a) [24]. The reflection coefficent $\left|S_{11}\right|$ of proposed design shown in Fig. 3 as dash red line, the array start to operate at $3 \mathrm{GHz}$ at reflection impedance bandwidth $\leq-10 \mathrm{~dB}$. Then quarter of the circular shap is etched as shown in Fig. 2(b) to improve the bandwith and the resonant frequency is reduced as shown in Fig. 3 (black line) to be resonated at $2.5 \mathrm{GHz}$.

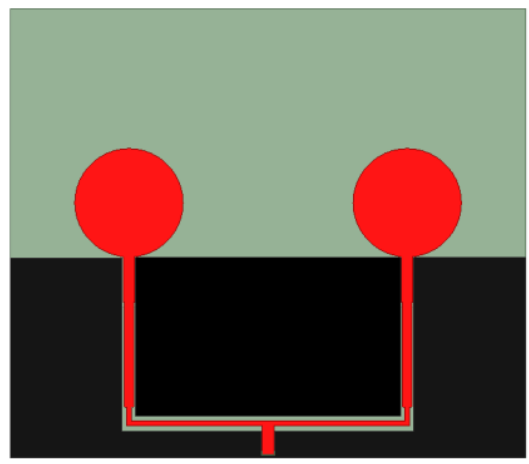

(a)

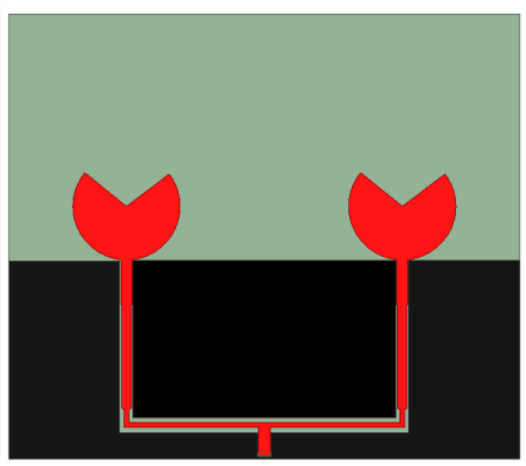

(b)

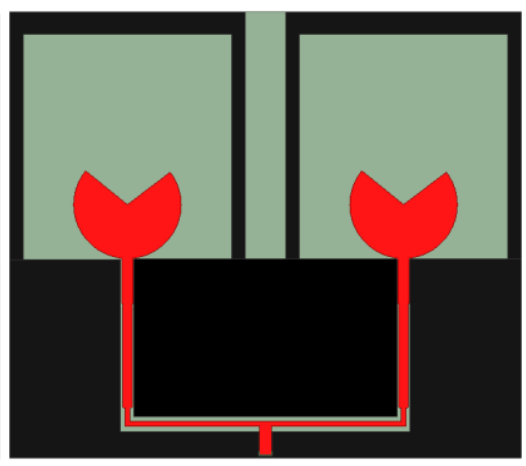

(c)

Fig.2. The design steps $2 \times 1$ anttenna array, (a) circular monopole, (b) modified circular and (c) slot antenna array.

The rectrangular strip is added around the antenna circular shape as shown in Fig. 2(c) to achieve ultrawideband as shown in Fig. 3 (blue dash dot line) bandwidth and the gain as well as reduced the resonant of the array to be at $1.7 \mathrm{GHz}$. Fig. 3 shows the reflection coefficient variation versus frequency for the three slot antenna array step design. The results indicate the improvement of 
bandwidth for each step of the design. The complete optimized dimensions of the $2 \times 1$ antenna array are shown in Table 1. In addition, the current distribution at different resonant frequencies of the RSAA are shown in Fig. 4. The highest magneitude of the current respresent the coresponding elements of the radiation.

Table 1:Dimensions of the $2 \times 1$ slot antenna array (all dimensions in $\mathrm{mm}$ ).

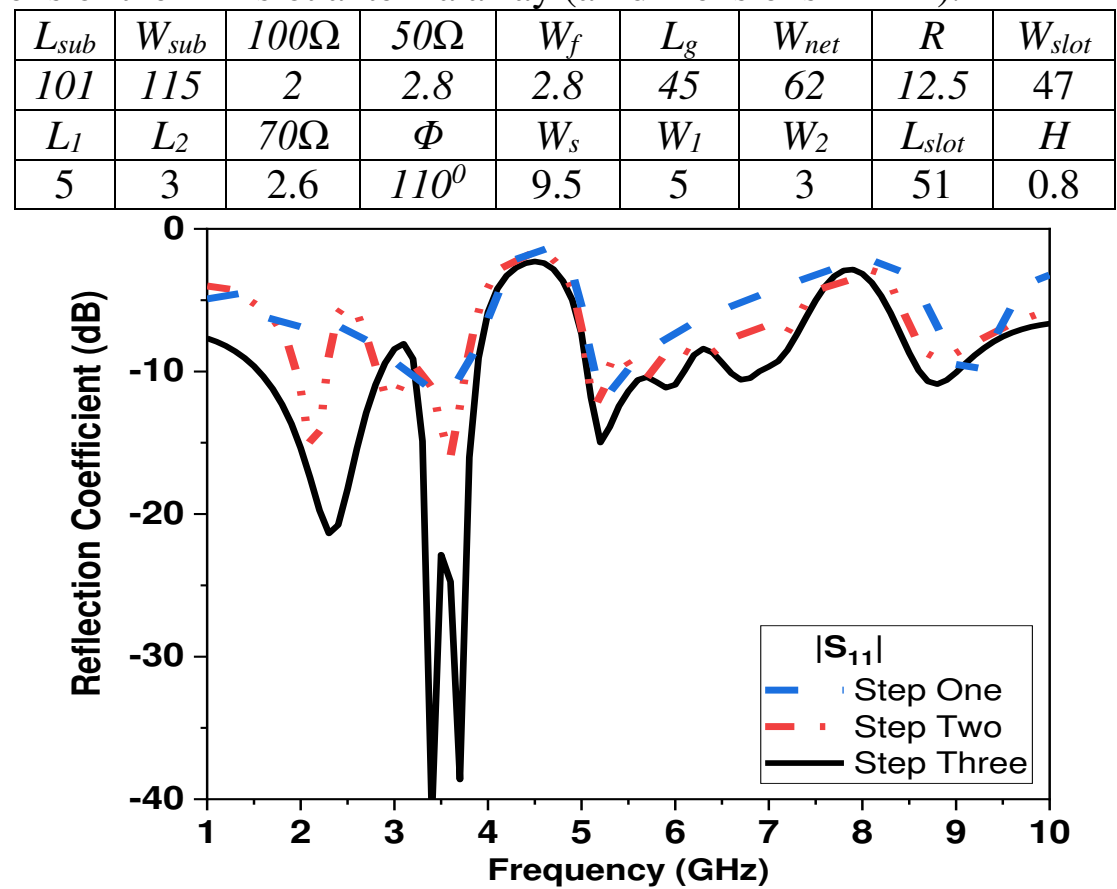

Fig.3. $\left|S_{11}\right|$ versus frequency for the design steps of the proposed antenna array.

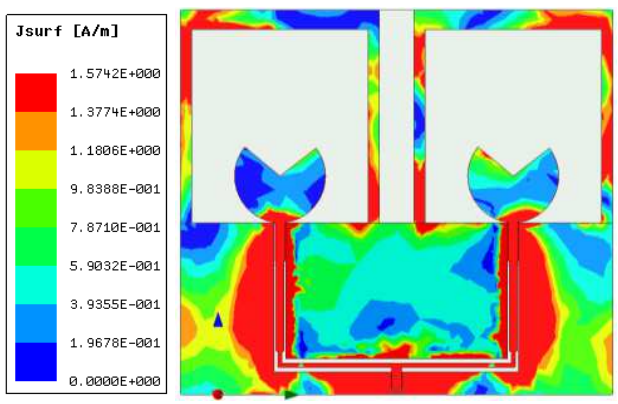

(a)

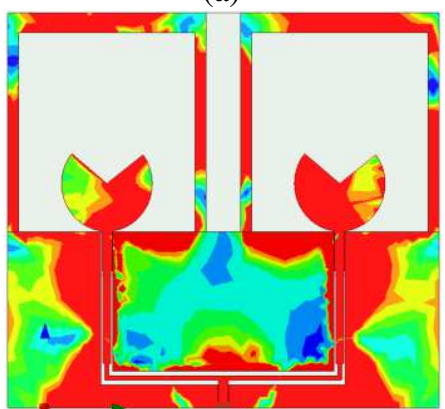

(d)

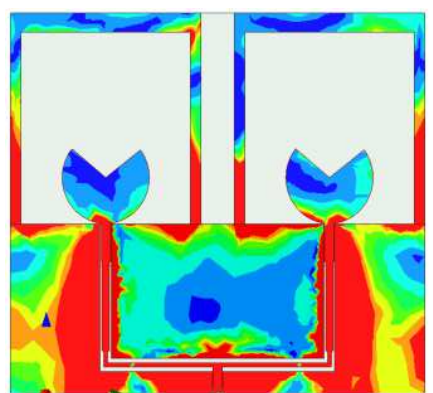

(b)

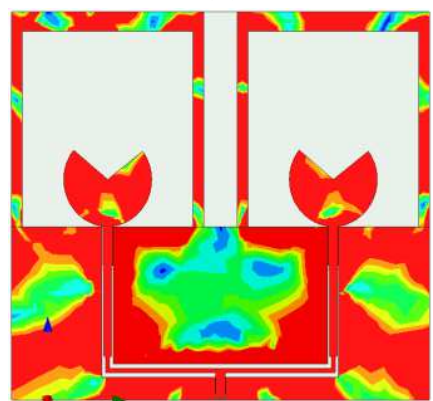

(e)

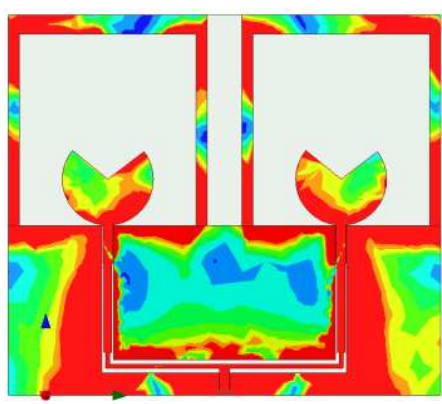

(c)

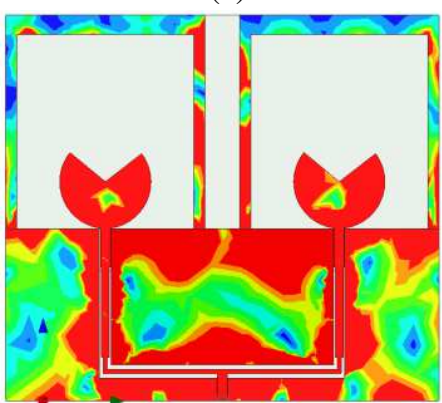

(f)

Fig.4. (a)-(f) Surface current distribution for proposed 2×1 RSAA at 1.8, 2.1, 2.45, 3.5, 5.2 and $7 \mathrm{GHz}$, respectively. 


\section{Method of Graphene Antenna}

The design of antenna arrays play a significant role in achieving high gain in a certain specified direction [13]. Moreover, Multiband designs offer an excellent opportunity to the system to serve more applications with the same physical components. The previous section described the proposed $2 \times 1$ antenna array. However, this section described the adding of two dimensions of graphene layer on the other side of the Roger substrate as a sandwich between the Roger substrate and silicon oxide substrate to reconfigurable the operating frequency.

\subsection{Graphene Conductivity Variation}

Graphene oxide (GO) has become important material as a result of its low cost, simple with various preparation techniques to be easily transformed to commercial graphene as RGO (reduced graphene oxide) [25-26]. 2D Graphene sheet is a material composed of highly conductive films with high mobility of $0.2 \mathrm{Mcm}^{2} \mathrm{v}^{-1} \mathrm{sec}^{-1}$ to enhance the antenna performance [27-28], [30]. Graphene sheet has a tuneable conductivity of about $10 \Omega / \square$ in the case of 20 voltage bias and about $1000 \Omega / \square$ in the case of zero voltage as shown in Fig. 5. The equivalent modelling circuit of the graphene layer has been presented as impedance $R_{g}$ and inductor $L_{g}$ in series. The values of graphene impedance vary according to applied bias voltage as shown in Fig.6. The changed of the graphene properties done by changing its resistance and inductance as shown in Fig. 6 which could be attributed to design tunable frequency of the antenna [31-34]. In this method of reconfigurabilty the frequency where the antenna exhibits the best input matching and the maximum gain could be adjusted electronically by modifying the voltage applied to graphene sheet.

$Z_{S}=\frac{1}{\sigma}$

$\sigma=\frac{\sigma_{o}}{\sigma(1+\mathrm{j} \omega \tau)}$

$\sigma_{o}=\frac{e^{2} K_{B} T \tau}{\pi \breve{\mathrm{h}}^{2}}\left[\frac{\mu_{c}}{K_{B}}+2 \ln \left(1+e^{-u_{c} / K_{B} T}\right)\right]$

$\breve{\mathrm{h}}$ is reduced Planck's constant, $\mathrm{K}_{\mathrm{B}}$ is Boltzmann's constant, $\mathrm{T}$ is the temperature, e is the electron charge, and $\mu_{\mathrm{c}}$ is the chemical potential. $\mathrm{T}=300 \mathrm{~K}$ and $\tau=0.1 \mathrm{Ps}$. $Z_{\mathrm{s}}$ is the surface impedance of the graphene, $\sigma$ is the conductivity of the graphene.

\subsection{Reconfigurable Graphene Antenna Array}

The radio technology of ultra wideband (UWB) is that uses transmitted very low energy for high data rate over a large portion of the radio spectrum. The other definitions of UWB is the antenna 
achieved bandwidth greater than $25 \%$ from the resonant frequency. There are many wireless applications cover these spectrum as four/five generation of wireless communications, so, the reconfigurable between these applications are very useful to cover and protected from channel fading and other losses. Since UWB offers higher data rates with lesser multipath interference at lower power levels as compared to the narrow band communication systems as shannon theorem [35]. So, it is therefore the preferred band for implementation for many $4 \mathrm{G}$ and $5 \mathrm{G}$ wireless communication services. The operating band of the proposed antenna is extended by applying the DC voltage bias on the graphene layer as shown in Fig. 7.

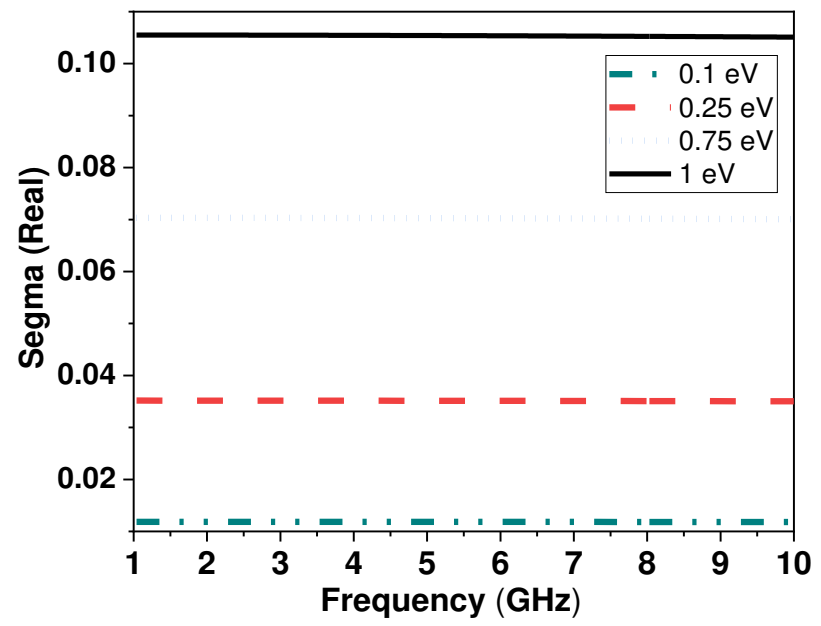

(a)

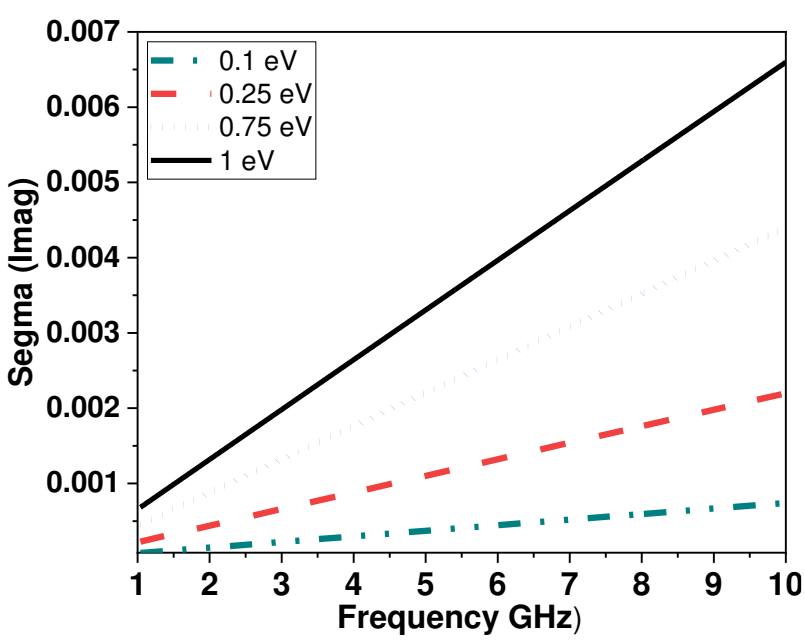

(b)

Fig. 5. Variation of conductivity with frequency of the graphene at different bias voltage, (a) real and (b) imaginary part.

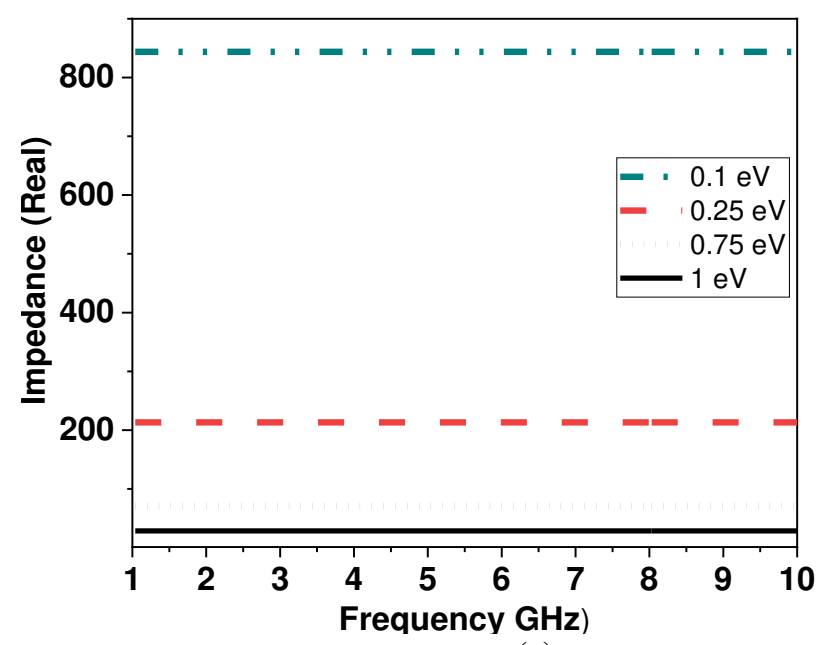

(a)

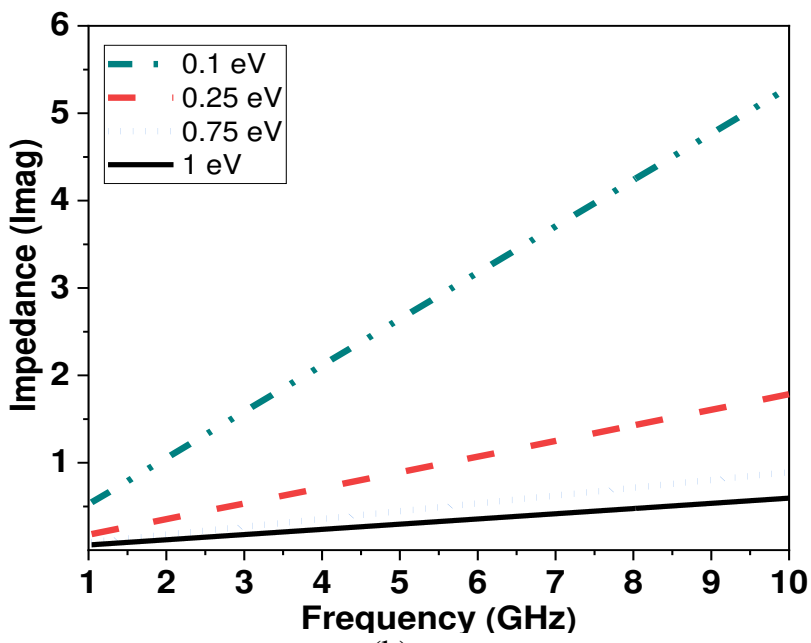

(b)

Fig. 6. Variation of impedance with frequency of the graphene at different bias voltage, (a) real and (b) imaginary part.

\section{Experimental of Antenna and Results}

The proposed array is designed and all simulations are done by using finite element three dimensions electromagnetic simulator, HFSS Ansys ver. 15 [29]. 


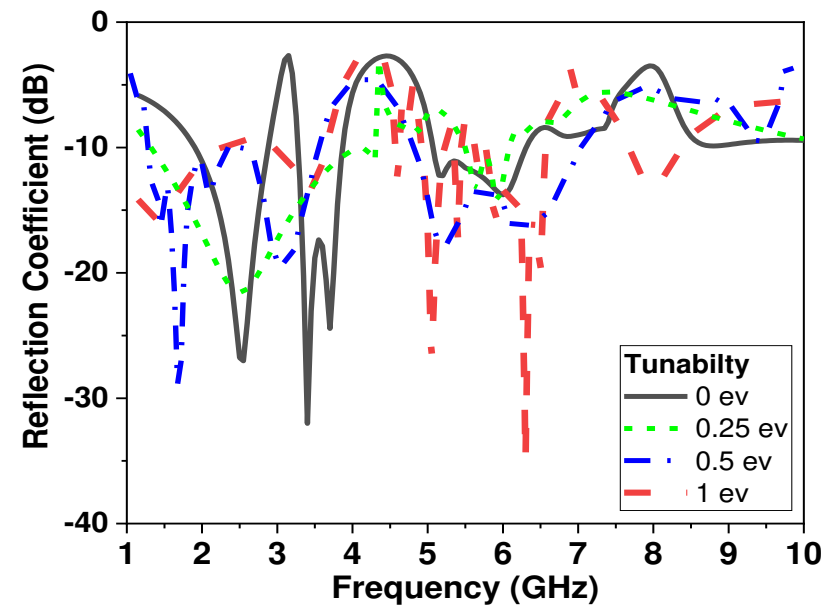

(a)

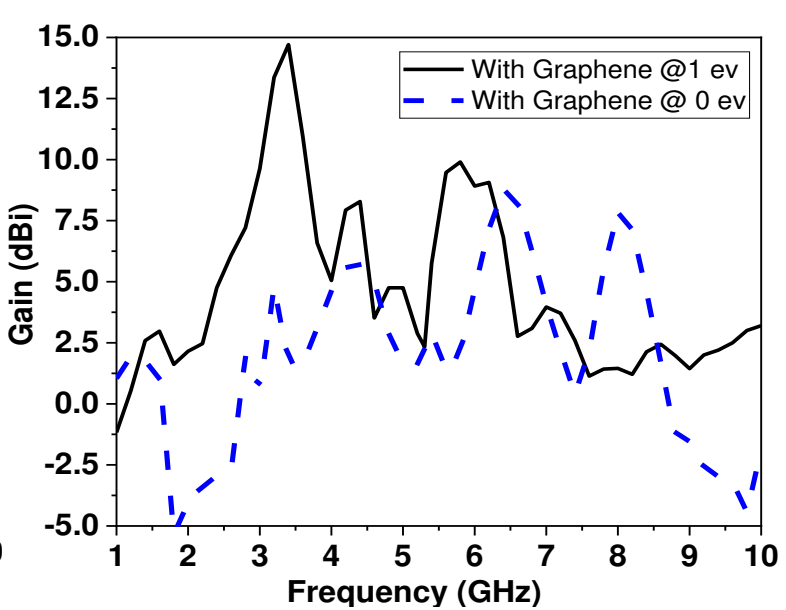

(b)

Fig. 7. Design procedures of the proposed array antenna with different graphene DC bias (a) $\left|S_{11}\right|$ and (b) gain.

To verify the simulation results; the proposed antenna array element is fabricated and measured by using ZVA67 Rohde and Schwarz vector network analyser from $10 \mathrm{MHz}$ up to $67 \mathrm{GHz}$ with different dc bias at 0 and 20 Volt as shown in Fig.8 by using bias Tee connector. Fig. 9 and Fig. 10 present the comparison between simulated reflection coefficient and voltage standing wave ratio (VSWR) variation versus frequency and measured result for the proposed RSAA at 0 and 20 Volt, respectively. These figures indicate that good agreements between measured and simulated. Fig. 9 shows the performance at 0 Volt and the $\left|S_{11}\right|<-10 \mathrm{~dB}$ array impedance bandwidth extend from 1.7 to $2.5 \mathrm{GHz}, 3.3$ to $3.8 \mathrm{GHz}$ and 5 to $7 \mathrm{GHz}$. While The operating band of the designed RSAA at DC 20 Volt bias the impedance bandwidth extend from $1.5 \mathrm{GHz}$ to $7 \mathrm{GHz}$ with stop bands from 4 to 5 GHz as shown in Fig. 10. These operating bands suitable for RF energy harvesting at GPS, GSM, UMTS, Wi-Fi, LTE bands and WMAX. The proposed array exhibits a nearly omnidirectional radiation pattern in the $\mathrm{E}$ and $\mathrm{H}$-plane at 0 Volt graphene bias as indicated in Table 2.

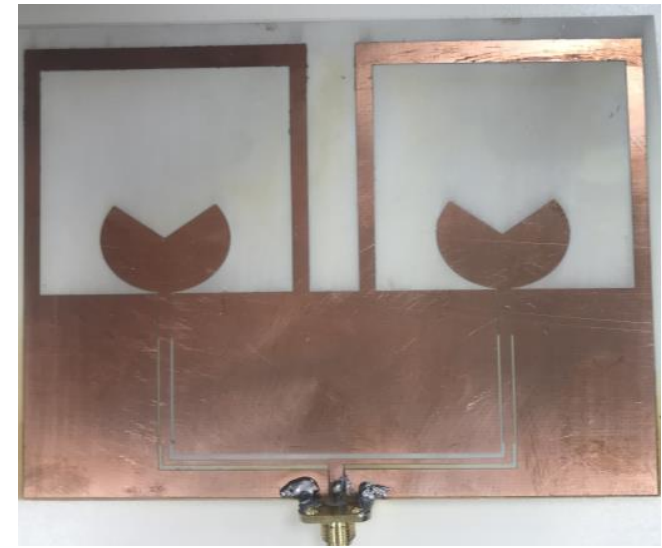

(a)

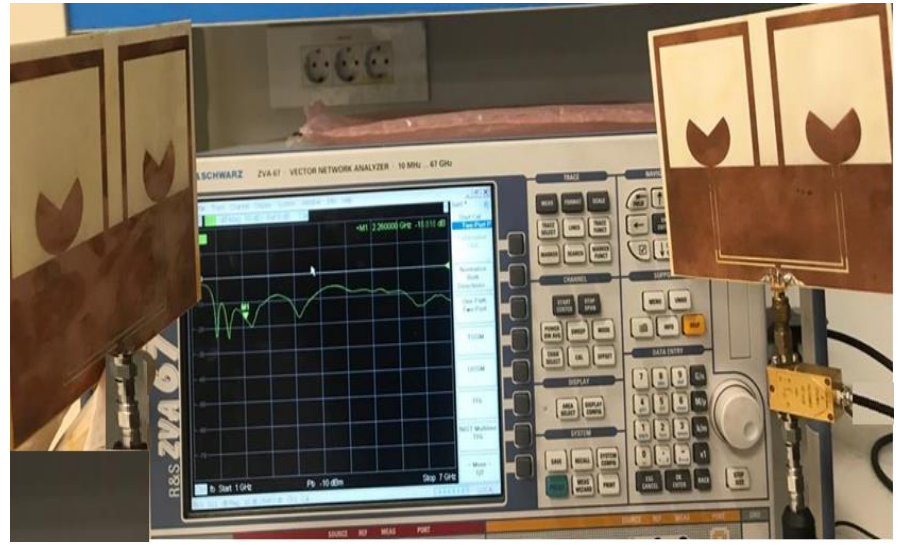

(b)

Fig. 8. Fabricated of RSAA (a) Photo of fabricated array and (b) setup measurement. 


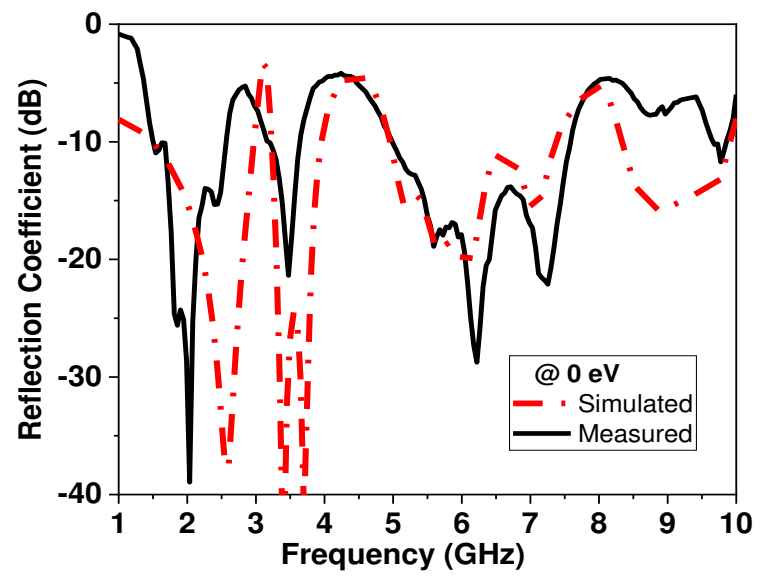

(a)

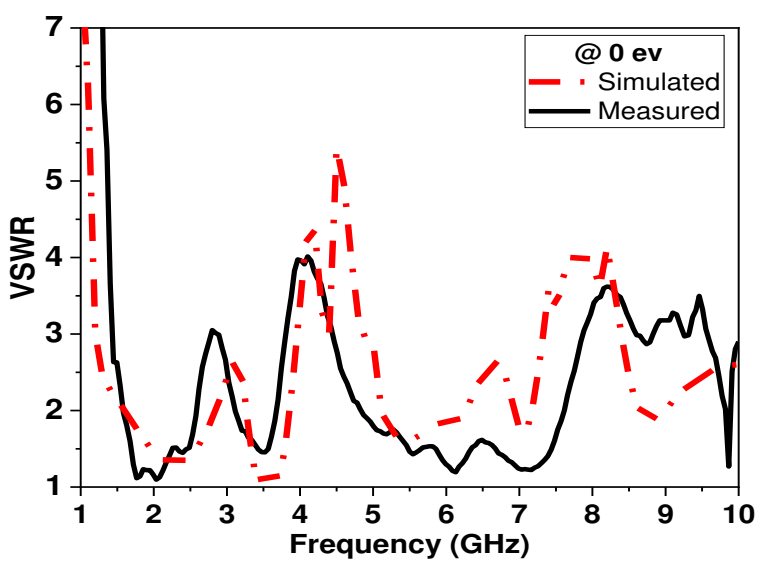

(b)

Fig. 9. The comparison between simulated and measured of RSAA at 0 Volt (a) $\left|\mathrm{S}_{11}\right|$ and (b) VSWR vs frequency.

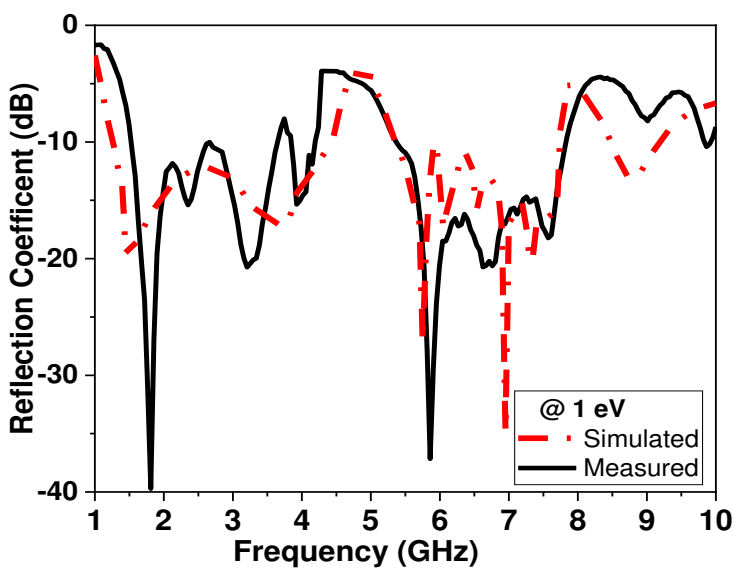

(a)

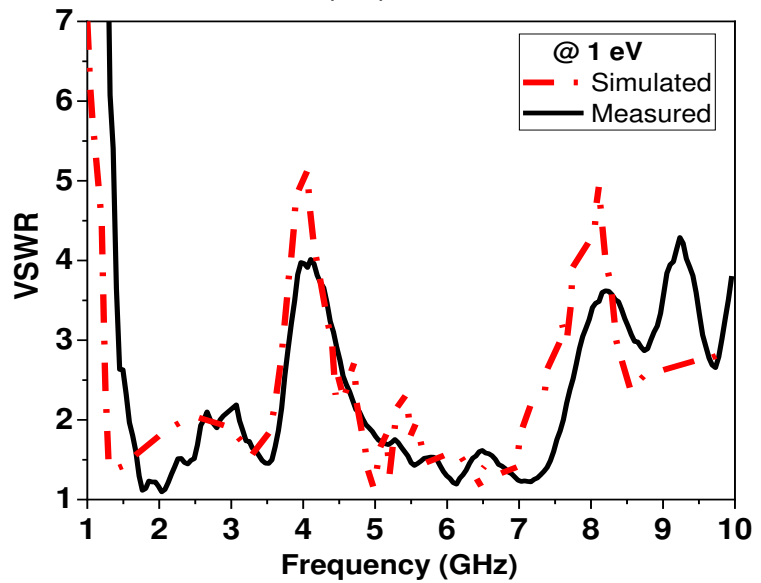

(b)

Fig. 10. The comparison between simulated and measured of RSAA at 20 Volt (a) $\left|S_{11}\right|$ and (b) VSWR vs frequency.

Table 2: Normalized simulated and measured radiation pattern $\mathrm{E}_{\theta}$ and $\mathrm{E}_{\Phi}$ for the proposed


A comparison of this proposed $2 \times 1$ rectangular slot antenna array with other reported arrays is provided in Table 3. It can be observed that the proposed array exhibits the ability to provide sufficient range of reconfigurable in most of wireless communication $4 \mathrm{G}$ and lower band of $5 \mathrm{G}$ frequency bands with increased gain and wide operating bandwidth by using single substrate in addition to the simplicity in the fabrication process.

Table 3: Comparison with other reported $2 \times 1$ SR antenna arrays.

\begin{tabular}{|c|c|c|c|c|c|}
\hline Parameters & [36] & [37] & [38] & [39] & This Work \\
\hline $\begin{array}{c}\text { Impedance } \\
\text { Bandwidth }(\mathrm{GHz})\end{array}$ & $2-3.2$ & $5.75-6.15$ & $2.35-2.45$ & $2.38-2.41$ & $1.5-4$ and $5-7$ \\
\hline $\begin{array}{c}\text { Antenna Array Gain } \\
(\mathrm{dBi})\end{array}$ & $\begin{array}{c}6.113 \mathrm{dBi} \text { at } \\
2.65 \mathrm{GHz}\end{array}$ & $\begin{array}{c}10.77 \mathrm{dBi} \text { at } 5.8 \\
\mathrm{GHz}\end{array}$ & $\begin{array}{c}9.24 \mathrm{dBi} \text { at } 2.4 \\
\mathrm{GHz}\end{array}$ & $\begin{array}{c}9.22 \mathrm{dBi} \text { at } 2.4 \\
\mathrm{GHz}\end{array}$ & $\begin{array}{c}15 \mathrm{dBi} \max . \text { at } 3.5 \\
\mathrm{GHz}\end{array}$ \\
\hline Group Delay & NM & NM & NM & NM & Less than $1 \mathrm{~ns}$ \\
\hline No. of Substrates & One & Two & One & One & One \\
\hline $\begin{array}{l}\text { Fabrication } \\
\text { Complexity }\end{array}$ & Simple & Complex & Simple & Simple & Simple \\
\hline $\begin{array}{l}\text { Feeding network } \\
\text { type }\end{array}$ & CPW & Microstrip & Microstrip & Microstrip & CPW \\
\hline Tunability & Yes & No & No & No & Yes \\
\hline Tuning Mechanism & $\begin{array}{c}\text { Graphene } \\
\text { sheet }\end{array}$ & No & No & No & $\begin{array}{c}\text { Graphene sheet } \\
\text { layer }\end{array}$ \\
\hline $\begin{array}{c}\text { Object Detection } \\
\text { Capability }\end{array}$ & No & No & No & No & Yes \\
\hline Circuit Size $\left(\mathrm{mm}^{3}\right)$ & $\begin{array}{c}101.88 \times 77.64 \\
\times 0.813\end{array}$ & $130 \times 80 \times 1.53$ & $180 \times 140 \times 1.6$ & $\begin{array}{c}110.5 \times 83 \times \\
1.56\end{array}$ & $115 \times 101 \times 0.8$ \\
\hline Circuit Size $\left(\lambda_{0}^{3}\right)$ & $\begin{array}{c}0.9 \times 0.68 \\
\times 0.007\end{array}$ & $\begin{array}{c}2.51 \times 1.54 \times \\
0.029\end{array}$ & $\begin{array}{c}1.44 \times 1.12 \times \\
0.0128\end{array}$ & $\begin{array}{c}0.884 \times 0.664 \\
\times 0.0125\end{array}$ & $0.7 \times 0.8 \times 0.0064$ \\
\hline
\end{tabular}

\section{RSAA Applications}

NM: Not mention in the reference paper.

\subsection{Group Delay}

Group delay is the series parameter of design UWB antenna for wireless communications. This it could be control the distortion of the transmitted pulses. The definition of the group delay is as the derivative with respect to frequency of the phase coupling between two identical UWB antennas $\left|\mathrm{S}_{21}\right|$ [34-38]:

$\tau=-\frac{\Delta \varphi}{\Delta \omega}=-\frac{1}{360^{0}} \frac{d \varphi(f)}{d f}$

The group delay should be close to a constant within the operation bands for perfect pulse transmission to obtain the phase linearity of the transmitted signals in the far field. The two antennas were aligned, and placed face to face orientation with separation distance between them greater than far field of the lowering operation bands as shown in Fig.11(a). The comparison results of $\left|S_{21}\right|$ for both measured and simulated HFSS results shown in Fig. 11. Fig.11(b) shows that the proposed 
antenna has perfect performance in this aspect and the group delay over the operating UWB band is less than $1 \mathrm{~ns}$ and the group delay and the magnitude transfer function are very flat in the whole band except in the notched bands which makes it quite suitable for UWB wireless applications.

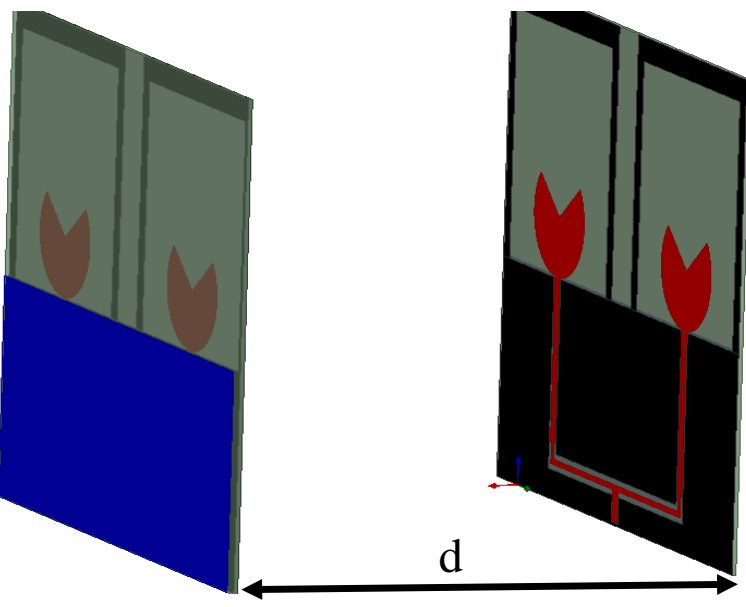

(a)

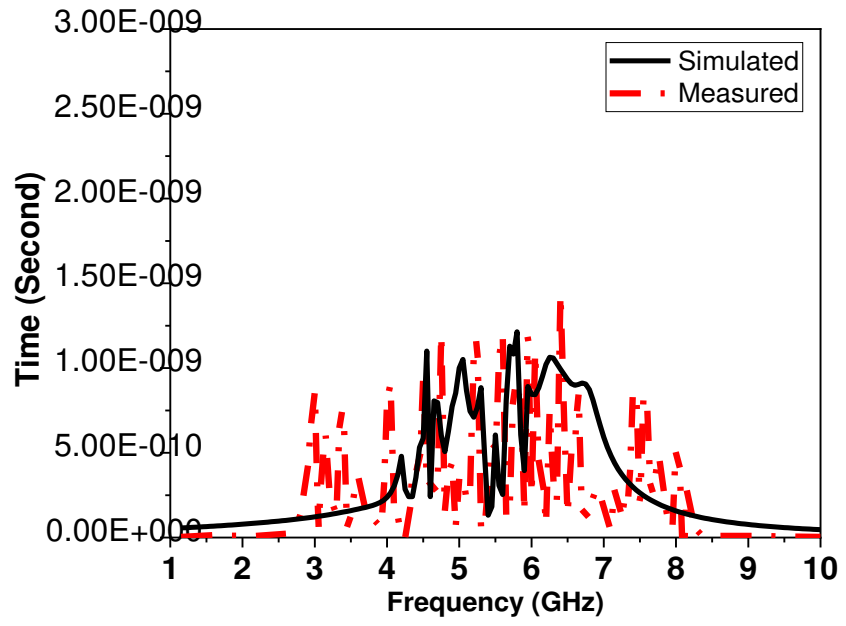

(b)

Fig. 11. Comparison between measured and simulated group delay of proposed $2 \times 1$ array antenna.

\subsection{Object Detection}

By using two face to face orientation as shown in Fig. 12(a) and placed different object with same size and different materials as perfect conductor, polyethylene and water in the far field region. The magnitude and the convolution angle could be changed of the transmission coefficient $\left|S_{21}\right|$ between both rectangular slot antenna arrays. Fig. 12(b) and 12(c) show that the maximum transmission obtain when the perfect conductor placed, however it gives less commutative angle. On the other side the water produces highest transmission at $4.5 \mathrm{GHz}$ and less transmission at frequency start from $6.5 \mathrm{GHz}$ with largest commutative angle. Fig. 13 shows the measured transmission coefficient magnitude and phase with three different objectives (perfect conductor, polyethylene and water) and compared with free space result.

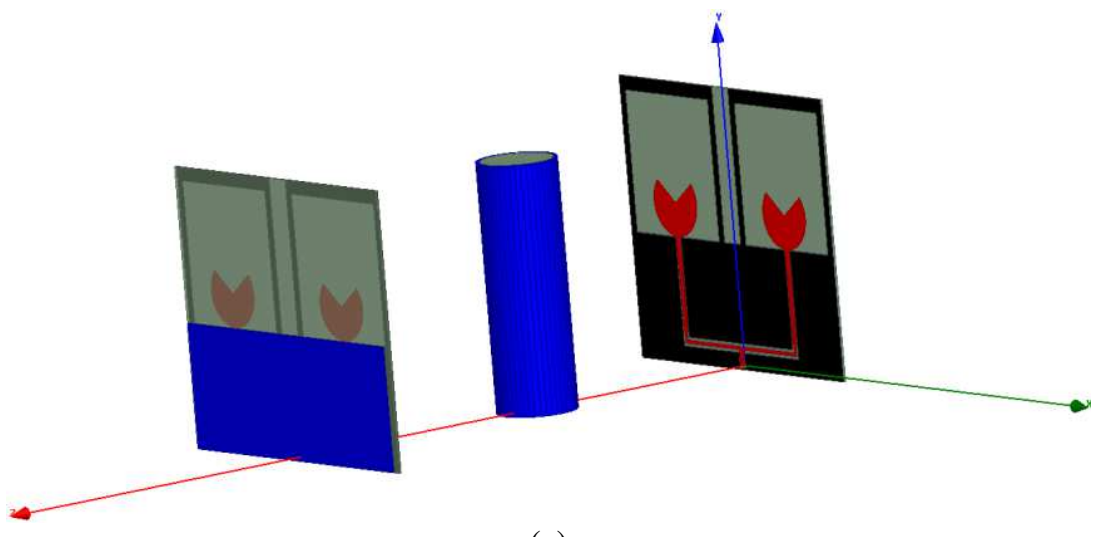

(a) 


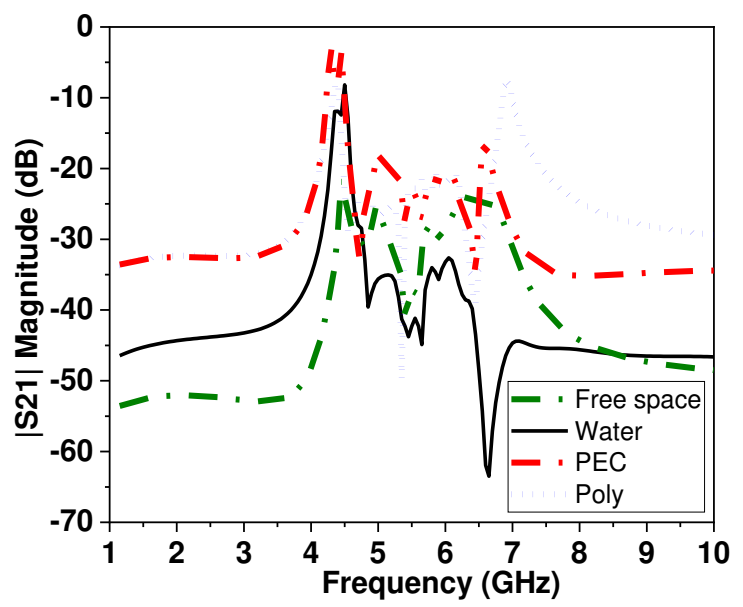

(b)

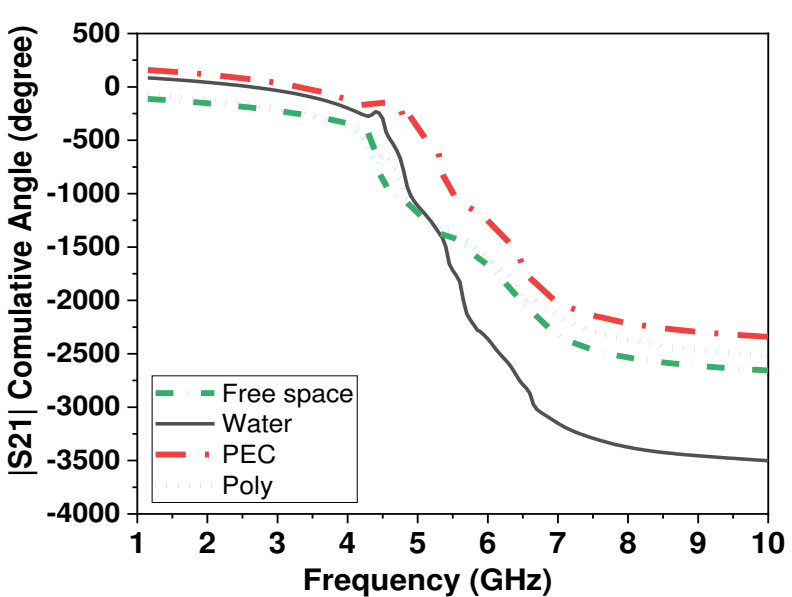

(c)

Fig. 12. (a) Simulated proposed array antenna detection system, (b) the $\left|S_{21}\right|$ transmission coefficient parameter magnitude and (c) Phase commutative angle.

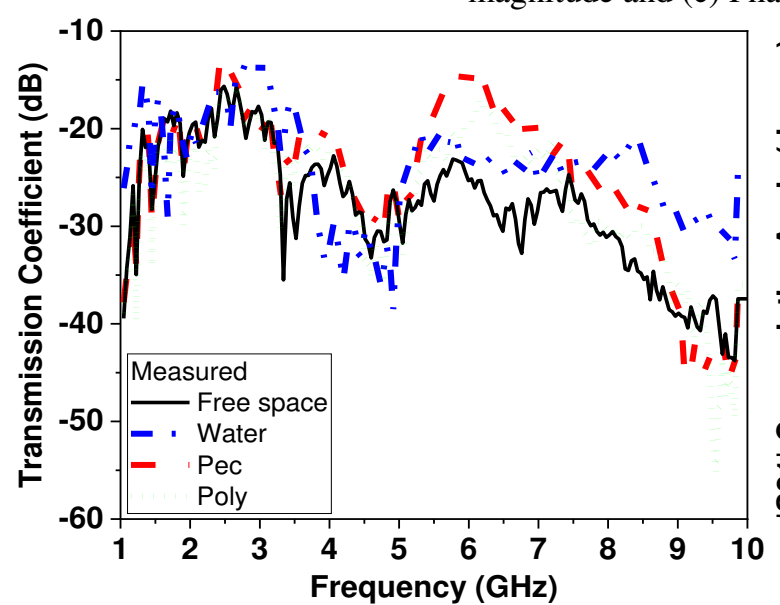

(a)

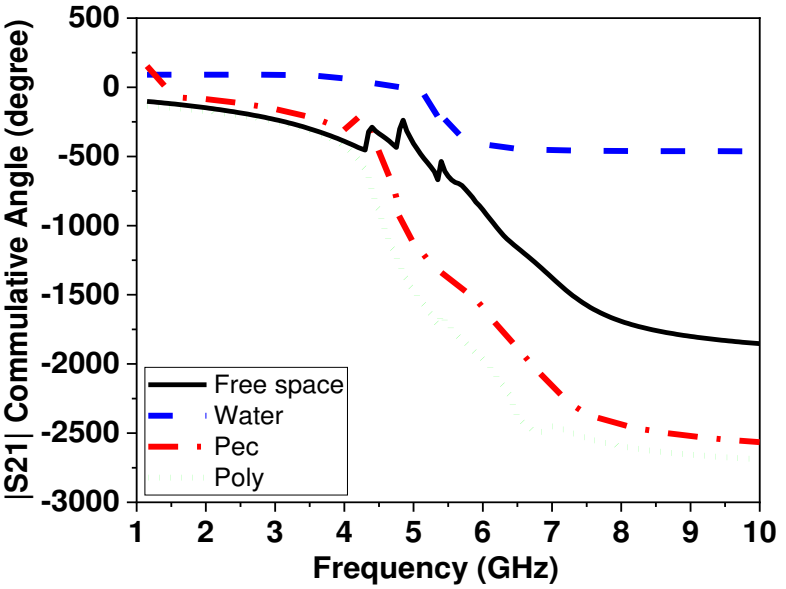

(b)

Fig. 13. Measured proposed array (a) Transmission coefficient magnitude and (b) Phase commutative angle.

\section{Conclusion}

A CPW rectangular slot $2 \times 1$ antenna array is presented in this paper with frequency range extend from 1.7 to $2.5 \mathrm{GHz}, 3.3$ to $3.5 \mathrm{GHz}$ and from 5.5 to $5.8 \mathrm{GHz}$ with average gain about $7.5 \mathrm{dBi}$ over the operating bands. Graphene sheet layer was added on the other substrate side under the $2 \times 1$ rectangular slot array feeding network to realize frequency reconfigurablility by applied DC bias. The reconfigurable frequency extend of lower band of $5 \mathrm{G}$ and other wireless communication bands. The operating frequency range extend from 1.5 to $3.5 \mathrm{GHz}$ to $4 \mathrm{G}$ bands and from 5 to 7 $\mathrm{GHz}$ with lower band of 5G. The proposed antenna array with omni-radiation pattern and the array gain improved by applying different DC voltages bias of the graphene sheet layer to be $15 \mathrm{dBi}$ at 20 volt. Experimental results have shown a range of reconfigurable and good agreement with the simulated results. The group delay of the proposed array is also studied, there was very good 
agreement between simulated and measured results and achieved less than 1ns over the operating band. Moreover, the proposed array is used for object detection and obtained good results to differentiate between different materials objectives.

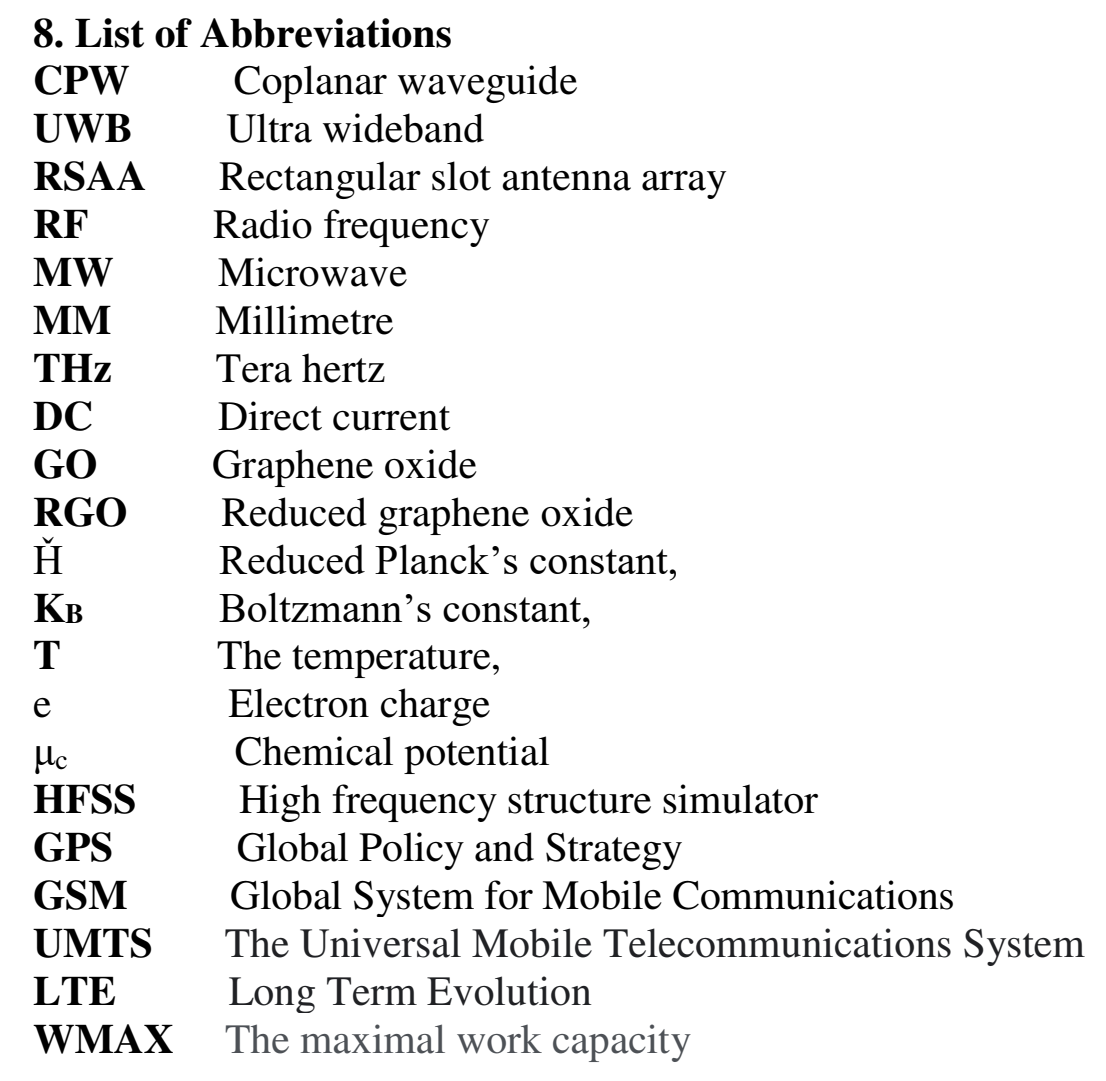

\section{Declarations}

-Availability of our proposed data and materials and all authors (Dalia Elsheakh and Osama Dardeer) must include an "Availability of Data and Materials" section in their manuscript detailing where the data supporting their findings can be found. Authors who do not wish to share their data must state that data will not be shared, and give the reason. If this is not applicable, please write: "Data sharing not applicable to this article as no datasets were generated or analysed during the current study.

-Competing Interest (Mandatory) for wireless communication applications

-All financial and there is non-financial support for this work 
-Dalia M. Elsheakh received the B.Sc., M.Sc. and Ph.D. degrees from Ain Shams University in 1998, 2005 and 2010, respectively. M.S. Thesis is on the design of Microstrip PIFA for Mobile Handsets. Ph.D. Thesis is in Electromagnetic Band-Gap Structure. From 2010 to 2015, she was Assistant professor and from 2016 until 2019 she is Associate Prof. in Microstrip Dept., Electronics Research Institute. From 2019 until now she is the head of Electronics and Communication Program in Faculty of Engineering and Technology, Badr University in Cairo. She was Assistant Researcher at Hawaii Center for advanced Communication (HCAC), College of Engineering, Hawaii University, USA at 2008 and Assistant Prof. at 2014 and 2018. Dr. Elsheakh has authored/co-authored four chapters in books. She has published 59 papers in peer-refereed journals and 50 papers in International Conferences. She is a member in many contracted projects (13 research and development project) funded from many funding agencies such as ASRT, NTRA, NSF, STDF, etc. She has three patents. She is an IEEE senior member from 2019.

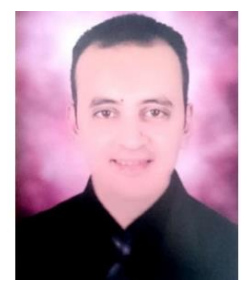

-Osama M. Dardeer was born in 1987. He received the B.S. degree with honor from the department of electronics and electrical communications engineering, Faculty of electronic engineering, Menofia University, Egypt, in 2009. He received the M.S. degree in electrical engineering from Ain Shams University, Egypt in 2017. He is currently an Assistant

Researcher at Microstrip Department, Electronics Research Institute, Egypt and aiming for getting a Ph.D. degree from Ain Shams University. He has been a member of research projects funded from national agencies such as National Telecommunication Regulatory Authority (NTRA). His research interests include UWB antennas, Antennas for Mobile Generations, Bandstop Filters, Radar Antenna Arrays, Power Dividers, Multiband Antennas, RF Energy Harvesting, Internet of Things applications, and Optical Switching Networks. (Email: osamadardeer@eri.sci.eg).

\section{References}

[1] M. Nejatijahromi, M. Rahman, and M. Naghshvarianjahromi, "Continuously tunable WiMAX band-Notched UWB antenna with Fixed WLAN Notched band,” Progress Electromagnet. Res. Lett., vol. 75, pp. 97-103, 2018.

[2] T. Li, H. Zhai, X. Wang, L. Li, and C. Liang, "Frequency reconfigurable bow-tie antenna for bluetooth, WiMAX, WLAN applications,” IEEE Antennas Wirel. Propag. Lett., vol. 14, pp. 171-4, 2015.

[3] B. Zhang, K. Song, B. Xu, Z. Luo, and B. Hu, "Compact reconfigurable bandpass filter with wide frequency tuning range," Electromagnetics, vol. 39, no. 2, pp. 89-98, 2019.

[4] A. A. Ibrahim, H. A. Mohamed, and W. A. E. Ali, "Tunable dual/triple band-pass filter based on stub-loaded resonators for wireless applications," J. Instrum, vol. 12, no. 4, pp. 04003, 2017. 
[5] A. Boutejdar, A. A. Ibrahim, and W. A. E. Ali, "Design of compact size and tunable band pass filter for WLAN applications,” Electron. Lett., Vol. 52, no. 24, pp. 1996-7, 2016.

[6] W. Peter Moo, D. J. DiFilippo, "Multifunction RF systems for naval platforms”, Sensors, 18(7), 2018.

[7] Xianjun Huang, Ting Leng, Jia Cing Chen, Kuo Hsin Chang, Zhirun Hu, "Shielding effectiveness of screen printed graphene laminate at C band", EuCAP'2016 in Davos, Switzerland.

[8] H. A. Atallah, A. B. Abdel-Rahman, K. Yoshitomi and R. K. Pokharel, "Design of miniaturized reconfigurable slot antenna using varactor diodes for cognitive radio systems," in Proceedings of the Fourth International Japan-Egypt Conference on Electronics, Communications and Computers (JEC-ECC), Cairo, pp. 63-66, 2016.

[9] Y. I. Abdulraheem et al., "Design of frequency reconfigurable multiband compact antenna using two PIN diodes for WLAN/WiMAX applications," IET Microwaves, Antennas \& Propagation. vol. 11, no. 8, pp. 1098-1105, 2017.

[10] V. Kumar, D. R. Jahagirdar, A. Basu and S. K. Koul, "Intra-band frequency reconfigurable antenna using RF MEMS technology," in Proceedings of the IEEE MTTS International Microwave and RF Conference, New Delhi, pp. 1-4, 2013.

[11] J. M. Floc'h and I. Ben Trad, "Printed planar double inverted-F antenna with large frequency reconfigurability range," in Proceedings of the European Radar Conference (EURAD), Nuremberg, 2017, pp. 441-444.

[12] X. 1. Yang, J. C. Lin, G. Chen and F. 1. Kong, "Frequency reconfigurable antenna for wireless communications using GaAs FET switch," IEEE Antennas and Wireless Propagation Letters, vol. 14, pp. 807-810, 2015.

[13] T. Leng, X. Huang, K. Chang, J. Chen, M. A. Abdalla, and Z. Hu, "Graphene nanoflakes printed flexible meanderedline dipole antenna on paper substrate for low-cost RFID and sensing applications," IEEE Antennas Wireless Propag. 7 Lett., vol. 15, pp. 1565-8, 2016.

[14] X. Huang, Z. Hu, and P. Liu, "Graphene based tunable fractal Hilbert curve array broadband radar absorbing screen for radar cross section reduction,” AIP. Adv., vol. 4, no. 11, pp. 117103, 2014.

[15] G.W. Hanson, “Dyadic Green's functions for an anisotropic, non-local model of biased graphene," IEEE Trans. Antennas Propag., Vol. 56, no. 3, pp. 747-57, 2008.

[16] D. Elsheakh "Reconfigurable frequency and steerable beam of monopole antenna based on graphene pads. International Journal of RF and Microwave Computer-Aided Engineering,", vol.30, Feb., 2020.

[17] Jin, Jiangliang \& Cheng, Zhiqun \& Chen, Jin \& Zhou, Tao \& Wu, Chunlin \& Xu, Chengjian. "Reconfigurable terahertz Vivaldi antenna based on a hybrid graphene-metal structure", International Journal of RF and Microwave Computer-Aided Engineering. vol.30. Dec., 2020.

[18] Yadav, Sachin, Kaur, Amanpreet, Khanna, Rajesh, “An ultra-wideband "OM” shaped DRA with a defected ground structure and dual polarization properties for $4 \mathrm{G} / 5 \mathrm{G}$ wireless communications", International Journal of RF and Microwave Computer-Aided Engineering, vol.30, 2020. 
[19] Jin Zhang, Zhenguo Liu, Weibing Lu, Hao Chen, Bian Wu, Qifeng Liu, "A low profile tunable microwave absorber based on graphene sandwich structure and high impedance surface", vol. 30, , 2020.

[20] X. Zhou, J. Le Kernec and D. Gray, "Vivaldi antenna for railway cutting monitoring," 2016 CIE International Conference on Radar (RADAR), Guangzhou, pp. 1-5, 2016

[21] G. W. Hanson, “Dyadic Green's functions for an anisotropic, non-local model of biased graphene," IEEE Trans. on Antennas Propag., vol. 56, no. 3, pp. 747-757, 2008.

[22] D. Elsheakh, and E. Abdallah, "Ultra-wide-bandwidth (UWB) microstrip monopole antenna using split ring resonator (SRR) structure", International Journal of Microwave and Wireless Technologies, 10(1), 123-132.

[23] A. A. A. Aziz, M. A. Abdalla and A. A. Ibrahim, "Enhanced Gain Tunable Two Elements Antenna Array Based on Graphene," 2018 IEEE International Symposium on Antennas and Propagation \& USNC/URSI National Radio Science Meeting, Boston, MA, pp. 471-472, 2018

[24] E. S. Angelopoulos, A. Z. Anastopoulos, D. I. Kaklamani, A. A. Alexandridis, F. Lazarakis and K. Dangakis, "Circular and elliptical CPW-fed slot and Microstrip-Fed antennas for ultrawideband applications," in IEEE Antennas and Wireless Propagation Letters, vol. 5, pp. 294-297, 2006

[25] Qurratul Ayn 1 , Dr. P.A. Nageswar Rao 2 , Prof. P. Mallikarjuna Rao 3, "Design and analysis of high gain $2 \times 1,4 \times 1,8 \times 1$ and $8 \times 8$ circular patch antenna arrays for $2.4 \mathrm{GHz}$ applications" International Journal of Innovative Research in Science, Engineering and Technology, vol. 6, Issue 8, August 2017.

[26] Aka CNM, Collardey SA, Mahdjoubi K. "An electrically small frequency reconfigurable antenna for DVBH” IEEE Int Workshop Antenna Technol. 2012, 245248.

[27] S. Wu, D. Zha, Y. He, L. Miao and J. Jiang, "Design of a Tunable absorber based on graphene in the THz range," 2019 IEEE International Conference on Computational Electromagnetics (ICCEM), Shanghai, China, pp. 1-3,2019

[28] C. Fan, B. Wu, Y. Hu, Y. Zhao and T. Su, "Millimeter-wave pattern reconfigurable vivaldi antenna using tunable resistor based on graphene," in IEEE Transactions on Antennas and Propagation, vol. 68, no. 6, pp. 4939-4943, June 2020

[29] www.ansys.com

[30] A. Q. Zhang, Z. G. Liu, L. Wei-Bing and H. Chen, "Graphene-based dynamically tunable attenuator on a coplanar waveguide or a slotline", IEEE Trans. Microw. Theory Techn., vol. 67, no. 1, pp. 70-77, Jan. 2019.

[31] A. K. Geim and K. S. Novoselov, “The rise of graphene," Nat. Mater., vol. 6, pp. 183-91, 2007.

[32] L.H. Jui \& L. Yinying, D. Huilian, S. Poman and B. Jens. "Time-domain modelling of group-delay and amplitude characteristics in ultra-wideband printed-circuit antennas" 10.1007/978-3-540-68768-9_19, 2008.

[33] D. Zhao, C. Yang, M. Zhu and Z. Chen, "Design of WLAN/LTE/UWB antenna with improved pattern uniformity using ground-cooperative radiating structure," in IEEE Transactions on Antennas and Propagation, vol. 64, no. 1, pp. 271-276, Jan. 2016. 
[34] J. Wu, Z. Zhao, Z. Nie and Q. Liu, "A Printed UWB vivaldi antenna using stepped connection structure between slot line and tapered patches," in IEEE Antennas and Wireless Propagation Letters, vol. 13, pp. 698-701, 2014.

[35] https://www.sciencedirect.com/topics/computer-science/shannon-sampling-theorem

[36] A. A. A. Aziz, M. A. Abdalla and A. A. Ibrahim, "Enhanced Gain Tunable Two Elements Antenna Array Based on Graphene," 2018 IEEE International Symposium on Antennas and Propagation \& USNC/URSI National Radio Science Meeting, Boston, MA, USA, 2018, pp. 471-472.

[37] A. B. Obot, G. A. Igwue, K.M. Udofia, "Design and simulation of rectangular microstrip antenna arrays for improved gain performance", International Journal of Networks and Communications, 9(2), pp.73-81, 2019

[38] Akaninyene B. Obot, Gabriel A. Igwue, and Kufre M. Udofia, "Design and Simulation of Rectangular Microstrip Antenna Arrays for Improved Gain Performance," International Journal of Networks and Communications, vol. 9, no. 2, pp.73-81, 2019.

[39] A. EL ALAMI, Y. GHAZAOUI, S. DAS, S. D. BENNANI, and M. EL GHZAOUI, "Design and simulation of RFID array antenna $2 \times 1$ for detection system of objects or living things in motion," International Workshop on Microwave Engineering, Communications Systems and Technologies (MECST), Leuven, Belgium, 2019, pp. 1010-1015. 